\title{
PENGARUH PEMBERIAN HANDOUT SEBELUM PERKULIAHAN TERHADAP HASIL BELAJAR FARMAKOLOGI KEBIDANAN PADA MAHASISWA DIII KEBIDANAN DI UNIVERSITAS KADIRI TAHUN 2015
}

(The Effect of Handout before Lecture on Midwifery Pharmacology Learning Results at Midwifery Diploma III Students at the Kadiri University in 2015)

\author{
Fitriana Yuni Permana Sari, Siti Aminah, Siswi Wulandari \\ Program D VI Kebidanan, Fakultas IImu Kesehatan, Universitas Kadiri Kediri \\ Email :fitrianayps@gmail.com
}

\begin{abstract}
ABSTRAK
Latar Belakang: Faktor penyebab kesulitan belajar mahasiswa adalah penguasaan konsep dan keterampilan mahasiswa yang belum tercapai sesuai keinginan. Studi pendahuluan menunjukkan bahwa mata kuliah farmakologi mendapat nilai rata-rata terendah 2,5 dari mata kuliah lain.Penelitian ini bertujuan mengetahui pengaruh pemberian handout sebelum perkuliahan terhadap hasil belajar mahasiswa.

Metode: Penelitianini adalah quasi eksperimen dengan "two group post-test only design". Sampel berjumlah 50 mahasiswa diambil dengan teknik total populasi sampling dari mahasiswa semester III D III Kebidanan Fakultas IImu Kesehatan Universitas Kadiri Tahun 2015. Instrumen yang digunakan adalah handout, powerpoint, dan soal-soal post-test.

Hasil: Analisis menggunakan SPSS 20 for Windows dengan uji statistik Mann Whitneymenghasilkan signifikansi $\rho=0,000$ dan $\alpha=0,05$ maka $\rho<\alpha$ yang berarti ada pengaruh pemberian handout sebelum perkuliahan terhadap hasil belajar mahasiswa. Hal ini menunjukkan bahwa hasil belajar mahasiswa yang mendapat handout sebelum perkuliahan mendapat kategori nilai Baik sebanyak 15 responden (30\%) lebih baik, dibandingkan dengan mahasiswa yang tidak mendapat handout sebelum perkuliahan yaitu sebanyak 13 responden (26\%) mendapat kategori nilai Buruk.

Kesimpulan:Pemberian handout sebelum perkuliahan dapat membantu mahasiswa lebih siap menerima materi di kelas karena mahasiswa dapat mempersiapkan diri sebelumnya sehingga mahasiswa dapat meningkatkan hasil belajarnya.
\end{abstract}

Kata Kunci : Handout, Hasil Belajar, Kebidanan

\section{ABSTRACT}

Introduction: The factors of the student learning difficulties are mastery of concepts andskills that have not been achieved as desired. The preliminary study showed that pharmacology subject received the lowest average score of 2.5 from other subjects. This study aims to determine the effect of giving handouts before lecturing on student learning outcomes.

Methods: This study was a quasi experiment with two group post-test only design. A sample of 50 students was taken with the total population sampling technique from semester III D III Midwifery students at the University of Health Faculty in 2015. The instruments used were handouts, powerpoints, and post-test questions.

Result and Discussion:The analysis using SPSS 20 for Windows with the Mann Whitney statistical testsignificance $\rho=0,000$ and $\alpha=0.05$ then $\rho<\alpha$, which means that there is an effect of giving handouts before lecturing on student learning outcomes. This shows that the learning outcomes of students who received a handout before the lecture received a Good value category of 15 respondents (30\%) better, compared to students who did not get a handout before the lecture, as many as 13 respondents (26\%) got the Bad value category.

Conclusion:Providing handouts before lectures can help students be better prepared to receive material in class because students can prepare themselves in advance so students can improve their learning outcomes.

Keywords: Handout, Learning Outcomes, Midwifery 


\section{PENDAHULUAN}

Undang-Undang RI No. 20 Bab II Pasal 3 Tahun 2003 tentang Sistem Pendidikan Nasional dijelaskan bahwa Tujuan Pendidikan Nasional berfungsi mengembangkan kemampuan dan watak serta peradaban bangsa yang bermartabat dalam rangka mencerdaskan kehidupan bangsa, mengembangkan potensi mahasiswa agar menjadi manusia yang beriman dan bertakwa kepada Tuhan yang Maha Esa, berakhlak mulia, sehat, berilmu, cakap, kreatif, mandiri, dan menjadi warga Negara yang demokratis serta bertanggung jawab (UU RI, 2003). Dua buah konsep kependidikan yang berkaitan satu dengan lainnya, yaitu belajar (learning) dan pembelajaran (intruction).Kegiatan belajar adalah harapan hasil yang baik dari dosen untuk suatu rangkaian pengajaran untuk mencapai dan meningkatkan prestasi belajar mahasiswa. Hasil dari proses belajar dapat dilihat dari hasil evaluasi mahasiswa yang berupa nilai test dari mata kuliah yang diajarkan (Paisal, 2013).

Data survei pendahuluan didapatkan nilai rata-rata semester III Tahun 2013 untuk mata kuliah Kespro \& KB 2, Asuhan Persalinan \& BBL, Asuhan Nifas \& Menyusui adalah 2,8, Asuhan Neo, Bayi, Balita \& Anak 3,0, Midwifery Update 3,3, dan Farmakologi Kebidanan 2,5. Hasil tersebut menunjukkan nilai rata-rata terendah adalah mata kuliah Farmakologi Kebidanan (Fikes, 2015).

Faktor penyebab kesulitan belajar mahasiswa adalah penguasaan konsep dan keterampilan mahasiswa belum tercapai sesuai dengan yang diinginkan. Dampaknya berupa kurangnya keaktifan mahasiswa dalam melakukan timbal balik; nilai mahasiswa yang rendah; tidak siapnya mahasiswa untuk tugas lahan; dan tidak lulus tepat waktu (Zainal, 2013).

Perbaikan dari sisi media pembelajaran dengancara pemberian handout sebagai bahan bacaan sebelum perkuliahan kepada mahasiswa diharapkan merangsang keinginan belajar dan meningkatkan kualitas belajar. Berdasarkan hal tersebut diatas maka penulis tertarik melakukan penelitianuntuk mengetahui Pengaruh Pemberian Handout Sebelum Perkuliahan Terhadap Hasil Belajar Farmakologi Kebidanan Bab Pengantar Farmakologi Kebidanan Mahasiswa D III Kebidanan Fakultas IImu Kesehatan Universitas Kadiri Tahun 2015.

\section{METODE PENELITIAN}

Penelitian ini adalahanalitik quasi eksperimen dengan desain "two group post-test only". Sampel penelitian diambil dengan teknik total samplingyaitu 50 mahasiswa.Penelitian dilaksanakan di Universitas Kadiri pada bulan September-November 2015. Variabel bebas dalam penelitian ini adalah Handout sebelum perkuliahan, dan variabel tergantungnya adalah hasil belajar. Sumber data dalam penelitian ini adalah primer dan sekunder.

Teknik pengolahan data dilakukan dengan caraediting, coding, entry, dan cleaning secara teliti serta dianalisis dengan uji Mann Whitney menggunakan Statistical Product and Service Solutions (SPSS) versi.22 for Windows(Lapau, 2013).Surat ijin penelitian dikeluarkan oleh Universitas Kadiri dengan Nomor 6032/FIKUNIK/IX/2015.

\section{HASIL DAN PEMBAHASAN}

Karakteristikresponden yang mendapat dan tidak mendapathandout berdasarkan usia dibagi menjadi 3 kategori yaitu usia 18-19 tahun, usia 20-21 tahun, dan usia 22-23 tahun.

Tabel.1 Distribusi Frekuensi Responden Yang Mendapat Dan Tidak MendapatHandout Berdasarkan Usia Mahasiswa D III Kebidanan Fakultas IImu Kesehatan Universitas Kadiri Tahun 2015

\begin{tabular}{lrr}
\hline Usia Mahasiswa & f & $\%$ \\
\hline Usia 18-19 tahun & 27 & 54 \\
Usia 20-21 tahun & 20 & 40 \\
Usia 22-23 tahun & 0 & 6 \\
\hline & 50 & 100 \\
\hline
\end{tabular}

Sumber : Data Primer 2015

Berdasarkan tabel 1 tersebut diatas menunjukkan bahwa sebagian besar dari responden berusia 18-19 tahun yaitu 27 responden $(54 \%)$ dan hampir setengahnya dari responden berusia berusia 20-21 tahun yaitu 20 responden (40\%).

Karakteristik responden yang mendapat dan tidak mendapat handout berdasarkan jurusan sekolah dibagi menjadi 3 kategori yaitu IPA, IPS, dan Lain-lain.

Tabel.2 Distribusi Frekuensi Responden Yang

Mendapat Dan Tidak Mendapatkan Handout

Berdasarkan Jurusan Sekolah MahasiswaD III Kebidanan Fakultas IImu Kesehatan Universitas Kadiri Tahun 2015

\begin{tabular}{|c|c|c|}
\hline Jurusan Sekolah & $f$ & $\%$ \\
\hline IPA & 29 & 58 \\
\hline IPS & 10 & 20 \\
\hline Lain-lain & 11 & 22 \\
\hline & 50 & 100 \\
\hline
\end{tabular}

Berdasarkan tabel 2 tersebut diatas menunjukkan bahwa sebagian besar dari responden ada di jurusan IPA yaitu 29 responden $(58 \%)$. Sedangkan sebagian kecil dari responden ada di jurusan IPS yaitu 10 responden $(20 \%)$, dan jurusan lain-lain yaitu 11 responden (22\%). 
Karakteristikhasil post-testresponden yang mendapat handout dibagi menjadi 4 kategori yaitu Istimewa, Baik Sekali, Baik, dan Buruk.

Tabel.3 Distribusi Frekuensi Post-test Responden Yang Mendapat Handout MahasiswaD III Kebidanan

Fakultas IImu Kesehatan Universitas Kadiri Tahun 2015

\begin{tabular}{lrr}
\hline \multicolumn{1}{c}{ Kategori } & $\mathrm{f}$ & $\%$ \\
\hline Istimewa & 1 & 2 \\
Baik Sekali & 0 & 0 \\
Baik & 21 & 42 \\
Buruk & 3 & 6 \\
\hline
\end{tabular}

Sumber : Data Primer 2015

Berdasarkantabel 3 tersebut diatas menunjukkan bahwa hampir setengahnya dari responden yang mendapat handout mendapat nilai post-test pada kategori Baik yaitu 21 responden $(42 \%)$. Sedangkan sebagian kecil dari responden berkategori Istimewa yaitu 1 responden $(2 \%)$, dan berkategori Buruk yaitu 3 responden $(6 \%)$.

Hasil analisis dengan program SPSS menginterpretasikan bahwa setengahnya dari responden yang mendapat handout mempunyai hasil belajar dengan kategori nilai baik sebanyak 21 responden (42\%). Paisal, 2013, memberi batasan media sebagai semua bentuk perantara yang digunakan oleh manusia untuk menyampaikan atau menyebarkan ide, gagasan atau pendapat sehingga ide, gagasan dan pendapat yang dikemukakan itu sampai kepada penerima yang dituju.

Kylua, 2013, berpendapat bahwa media adalah segala alat fisik yang dapat menyajikan pesan serta merangsang mahasiswa untuk belajar. Pemberian media pembelajaran mempunyai syarat dan ketentuan yang diterapkan dengan tujuan untuk mempermudah peserta didik menerima dan memahami materi yang diberikan. Handout adalah tulisan secara singkat yang berisi bahan ajar yang akandisampaikan. Handout yang digunakan untuk mempermudah proses penyampaian materi pelajaran yang ada pada powerpoint. Handout adalah tulisan yang dibuat oleh dosen yang berisikan tentang tujuan dan sasaran pembelajaran. Handout merupakan media belajar di dalam proses pembelajaran yang berisi materi pembelajaran berupa bagan, gambar dan penjelasan singkat.

Hal ini dapat diartikan bahwa pemakaian media yang mudah, efektif dan jelas akansangat membantu mahasiswa untuk dapat menerima materi dengan baik dan mudah dipahami sebagai media pembelajaran. Dengan alasan tersebut maka handout diberikan sebagai media pembelajaran alternatif yang dianggap mudah untuk membantu proses pembelajaran untuk meningkatkan hasil belajar mahasiswa.
Karakteristik hasil post-testresponden yang tidak mendapat handout juga dibagi menjadi 4 kategori yaitulstimewa, Baik Sekali, Baik, dan Buruk.

Tabel.4 Distribusi Frekuensi Post-test Responden Yang Tidak Mendapat Handout MahasiswaD III Kebidanan Fakultas IImu Kesehatan Universitas Kadiri Tahun 2015

\begin{tabular}{lrr}
\hline \multicolumn{1}{c}{ Kategori } & $\mathrm{f}$ & $\%$ \\
\hline Istimewa & 0 & 0 \\
Baik Sekali & 0 & 0 \\
Baik & 5 & 10 \\
Buruk & 20 & 40 \\
\hline
\end{tabular}

Sumber : Data Primer 2015

Berdasarkan tabel 4 tersebut diatas menunjukkan bahwa hampir setengahnya dari responden yang tidak mendapat handout mendapat nilai post-test pada kategori Buruk yaitu 20 responden (40\%) dan sebagian kecil dari responden mendapat nilai dengan kategori Baik yaitu 5 responden (10\%).

Mahasiswa yang tidak mendapat handout diinterpretasikan bahwa hampir setengahnya responden yang tidak mendapat handout mempunyai hasil belajar dengan kategori nilai Buruk sebanyak 20 responden (40\%). Menurut Abdullah, 2011, hasil belajar adalah kemampuan. Kemampuan yang dimiliki mahasiswa setelah dia mengalami pengalaman belajarnya. Howard Kingsley dalam Abdullah, 2011, membagi tiga macam hasil belajar yakni keterampilan dan kebiasaan; pengetahuan dan pengertian; sikap dan cita-cita. Hasil belajar dapat berupa dampak pengajaran, hasil yang dapat diukur seperti tertuang dalam nilai.

Salah satu faktor yang dapat mempengaruhi hasil belajar dari pengalaman sebelumnya adalah jurusan saat sekolah yang diambil. Tingkah laku sebagai hasil belajar dalam pengertian yang luas mencakup bidang kognitif, afektif dan psikomotor. Bloom dan rekanrekannya membagi hasil belajar dalam tiga ranah yaitu ranah kognitif, ranah afektif dan ranah psikomotor. Hal ini diartikan bahwa pengalaman belajar dapat mempengaruhi pengetahuan dan pemahaman materi dalam pembelajaran. Faktor yang dapat mempengaruhi hal tersebut adalah kemungkinan dari masa lalu yang sebelumnya pernah menerima materi yang berhubungan dengan materi saat ini yang diberikan (Zainal, 2013).

Hasil analisis data tabulasi silang menggunakan uji Mann Whitney pada Mahasiswa Yang Mendapat dan Tidak Mendapat Handout dengan 4 kategori Hasil Belajar. 
Tabel.5 Tabulasi Silang Pemberian Handout Dengan Hasil Belajar Mahasiswa D III Kebidanan Fakultas IImu Kesehatan Universitas Kadiri Tahun 2015

\begin{tabular}{|c|c|c|c|c|c|c|c|c|}
\hline \multirow{3}{*}{ Hasil Belajar } & \multicolumn{6}{|c|}{ Kategori Nilai } & & \\
\hline & \multicolumn{2}{|c|}{ Istimewa } & \multicolumn{2}{|c|}{ Baik } & \multicolumn{2}{|c|}{ Buruk } & \multicolumn{2}{|c|}{ Jumlah } \\
\hline & $f$ & $\%$ & $\mathrm{~F}$ & $\%$ & $f$ & $\%$ & $\mathrm{~F}$ & $\%$ \\
\hline $\begin{array}{l}\text { Mendapat } \\
\text { Handout } \\
\text { Tidak }\end{array}$ & 1 & 2 & 21 & 42 & 3 & 6 & 25 & 50 \\
\hline $\begin{array}{l}\text { Mendapat } \\
\text { Handout }\end{array}$ & 0 & 0 & 5 & 10 & 20 & 40 & 25 & 50 \\
\hline Jumlah & 1 & 2 & 26 & 52 & 23 & 46 & 50 & 100 \\
\hline
\end{tabular}

Berdasarkan tabel 5 diatas menunjukkan bahwa setengahnya dari responden yang mendapat handout mempunyai hasil belajar dengan kategori nilai Baik sebanyak 21 responden (42\%). Sedangkan hampir setengahnya responden yang tidak mendapat handout mempunyai hasil belajar dengan kategori nilai Buruk sebanyak 20 responden (40\%).

Hasil tabulasi silang untuk Pengaruh Pemberian Handout Sebelum Perkuliahan Terhadap Hasil Belajar Mahasiswa diinterpretasikan bahwa setengahnya dari responden yang mendapat handout mempunyai hasil belajar dengan kategori nilai Baik sebanyak 21 responden (42\%). Sedangkan hampir setengahnya responden yang tidak mendapat handout mempunyai hasil belajar dengan kategori nilai Buruk sebanyak 20 responden (40\%)

Hasil analisis dari Mann Whitney pada a $(0,05)$ dan $\rho$ value $(0,000)$ maka dapat disimpulkan bahwa $\mathrm{HO}$ ditolak dan $\mathrm{H} 1$ diterima artinya ada pengaruh pemberian handout sebelum perkuliahan terhadap hasil belajar farmakologi kebidanan bab pengantar farmakologi kebidanan mahasiswa D III Kebidanan Fakultas IImu Kesehatan Universitas Kadiri tahun 2015.

Hamalik dalam Zainal 2013, mengemukakan bahwa pemakaian media pembelajaran dalam proses pembelajaran dapat membangkitkan keinginan dan minat yang baru, membangkitkan motivasi dan rangsangan kegiatan belajar dan bahkan membawa pengaruh-pengaruh psikologis terhadap mahasiswa. Penggunaan media pada tahap orientasi pembelajaran akan sangat membantu keefektifan proses pembelajaran dan penyampaian pesan dari isi pelajaran. Disamping membangkitkan motivasi dan minat mahasiswa, media pembelajaran juga membantu siswa meningkatkan pemahaman menyajikan data dengan menarik dan terpercaya, mudah menafsirkan data dan memadatkan data.

Winkel dalam Zainal 2013,

mengemukakan bahwa setiap macam kegiatan belajar menghasilkan suatu perubahan yang khas, yang disebut hasil belajar. Tingkah laku sebagai hasil belajar dalam pengertian yang luas mencakup bidang kognitif, afektif dan psikomotor.Menurut Nana Sudjana, 2009, hasil belajar adalah kemampuan. Kemampuan yang dimiliki mahasiswa setelah dia mengalami pengalaman belajarnya. Belajar merupakan suatu proses internal yang mencakup ingatan, retensi, pengolahan informasi, emosi dan faktor-faktor lain. Belajar, mencakup pengaturan stimulus yang diterima dan disesuaikan dengan struktur kognitif yang terbentuk di dalam pikiran seseorang berdasarkan sebelumnya.

pengalaman-pengalaman

Hasil penelitian ini menunjukkan bahwa pemberian handout sebelum perkuliahan dapat mempengaruhi hasil belajar mahasiswa, dimana pada tabulasi silang dapat diketahui bahwa responden yang mendapat handout sebelum perkuliahan berhasil mendapatkan nilai lebih baik, hal ini terjadi karena dengan pembelajaran kognitif yaitu retensi pengetahuan baru yang merupakan fungsi dari struktur kognitif yang telah dimiliki mahasiswa.

Berdasarkan hasil penelitian diatas sebagian besar responden yang mendapat handout sebelum perkuliahan memperoleh hasil belajar dengan kategori nilai istimewa dan baik, sedangkan responden yang tidak mendapat handout sebelum perkuliahan memperoleh hasil belajar dengan kategori nilai buruk lebih besar dari pada kategori nilai istimewa dan baik. Hal ini terjadi karena responden yang tidak mendapat handout sebelum perkuliahan tidak mempunyai retensi pengetahuan sebelumnya (Natalia, 2013). Sehingga diasumsikan bahwa pemberian handout yang diberikan sebelum perkuliahan telah memberikan struktur kognitif tentang bahan perkuliahan yang akan diberikan. Artinya, retensi pengetahuan baru pada mahasiswa yang bersangkutan akan lebih baik dari pada tanpa pemberian handout sebelum perkuliahan.

Keterbatasan dalam penelitian ada dua hal yaitu jumlah responden yang awalnya 54 responden menjadi 50 reponden karena 4 responden mengundurkan diri pada awal perkuliahan sehingga terdapat pengurangan sampel. Keterbatasan kedua adalah jarak pemberian handout kepada responden terlalu dekat sehingga waktu belajar yang mereka dapatkan kurang efisien. 


\section{KESIMPULAN}

Berdasarkan hasil uji statistik penelitian menyatakan signifikansi bahwa $\mathrm{HO}$ ditolak dan $\mathrm{H} 1$ diterima artinya ada pengaruh pemberian handout sebelum perkuliahan terhadap hasil belajar farmakologi kebidanan bab pengantar farmakologi kebidanan mahasiswa D III Kebidanan Fakultas IImu Kesehatan Universitas Kadiri tahun 2015. Hal tersebut menyimpulkan bahwa pemberian handout sebelum perkuliahan dapat membantu mahasiswa lebih siap menerima materi di kelas karena mahasiswa dapat mempersiapkan diri sebelumnya sehingga mahasiswa dapat meningkatkan hasil belajarnya Hasil penelitian diharapkanresponden memanfaatkan media pembelajaran yang diberikan oleh pendidik sehingga dapat mengasah ranah koginitifnya. Selain itu penelitian ini diharapkan dapat dijadikan literature dalam rangka pengembangan kualitas pendidikan dan pemilihan strategi memperbaiki hasil belajarpeserta didik. Dan untuk peneliti selanjutnya diharapkan dapat menyempurnakan hasil penelitian dengan melakukan pengkajian lebih dalam.

\section{DAFTAR PUSTAKA}

\section{Abdullah, Helmy.2011. Teori Belajar Kognitif dan Aplikasinya Dalam Pembelajaran Bahasa, diakses tanggal 5 Juli 2015, http://jlt- polinema.org/?tag=teori-belajar- kognitif.}

Kylua, 2013, Teori Pendidikan Belajar Kognitif, diakses tanggal 6 Juli 2015, https://kylua.wordpress.com/pen didika/teori-belajar-kognitif/.

Lapau, Buchari, 2013, Metode Penelitian Kesehatan, Jakarta, Yayasan Pustaka Obor Indonesia.

Natalia, Reny, 2013, Metode Mengajar Pemberian Tugas, diakses tanggal 12 Juli 2013, http://rennynataliaa.blogspot.co m/files/2013/04/metodemengajar-pemberian-tugas.

Paisal, Agus,2013,"Pengaruh Pemberian Handout Dalam Meningkatkan Hasil Belajar Matematika Siswa MTs Kelas VII", http://repository.uinjkt.ac.id/dspace/ bitstream/123456789/9465/1/AGU S\%20PAISAL-FITK.pdf.
Presiden,
2003.
Undang-

UndangRepublikIndonesiaNom

or20Tahun 2003

TentangSistemPendidikanNasio nal, diakses tanggal 20 Juni 2015 ,

https://referensi.elsam.or.id/2014/1 1/uu-nomor-20-tahun-2003tentang-sistem-pendidikannasional/.

Prodi D III Kebidanan, 2015, Nilai Semester Per-Mata Kuliah, Fakultas IImu Kesehatan, Universitas Kadiri Kediri.

Sudjana, Nana, 2009, Penilaian Hasil Proses Belajar Mengajar, Bandung, PT. Remaja Rosdakarya.

Zainal, Aqib, 2013, Model-model, Media, dan Strategi Pembelajaran Konstekstual (Inovatif), Bandung, CV Yrama Widya. 